\title{
In-field determination of drag through grass for a forest-fire simulation model
}

\author{
P. M. Kenney ${ }^{1}$, T. G. Keith ${ }^{1}$, T. T. $\mathrm{Ng}^{1}$ \& R. R. Linn ${ }^{2}$ \\ ${ }^{I}$ Department of Mechanical, Industrial, and Manufacturing Engineering, \\ University of Toledo, Toledo, Ohio, USA \\ ${ }^{2}$ Los Alamos National Laboratory, Los Alamos, New Mexico, USA
}

\begin{abstract}
Forest-fire simulation modelers need fluid-drag data for ground vegetation; however, very little such data is to be found. Further, the gathering of such data using experimental facilities such as large flumes is time, labor, and equipment intensive. This paper presents an initial investigation of a plant-drag measurement procedure which can be carried directly to native plant communities. Instead of using large flumes and potted plants with load cells attached, this work will verify that a portable wind tunnel can be used to determine the difference in total pressure across a stand of vegetation. The total pressure difference can then be equated to the drag through that stand and a drag coefficient determined as a function of the Reynolds number. Vegetal parameters considered in determining a drag coefficient are percentage cover, fractal dimension, and lacunarity. Vorticity and flow through the plant canopy causing plant oscillation are not considered because of the limited height of the tunnel used and because of honeycomb flow straighteners used in the apparatus which destroy vorticity and alter the velocity profile.
\end{abstract}

Keywords: plant drag, in-situ data collection, fractals, lacunarity, total pressure, wind tunnel.

\section{Introduction}

The need for drag coefficient data for grasses, forbs, etc. (and the lament of the lack thereof) exists in the studies of water flow in plant-filled, open channels and cultivated flood plains awash with spring flooding [1], of wind lodging (overturning) in crops $[2,3]$, of soil erosion windbreaks, and of inter- and 
intraplant air flow in wildland fire simulation. This work is being performed to address the latter - particularly the FIRETEC model [4]; but hopefully, will be useful in the other arenas.

One might ask: Why would one need to know a grass drag coefficient for a forest-fire model when the wind driving a fire forward is not hindered by the already burnt grass? The answer is that a fire draws air into itself from all directions - including through the unburnt vegetation downwind of the fire.

\section{Objective of this work}

There are two main goals for this work. The primary one is to develop a drag coefficient model for flow through ground vegetation. Such a model should address vegetation density and aggregation. A secondary goal is to determine if in-field data gathering is feasible by measuring the change in total pressure using a portable wind tunnel.

\section{Total pressure change as a measure of drag}

Total pressure, $p_{o}$, (the sum of static pressure, $p$, and dynamic pressure $\rho v^{2} / 2$; where $\rho$ and $v$ are the density and velocity of the fluid), measurement has been used in wind tunnel determination of drag for some time in the form of wake surveys [5]. That method is a variant of the theory as described next which is presented in two dimensions for simplicity.

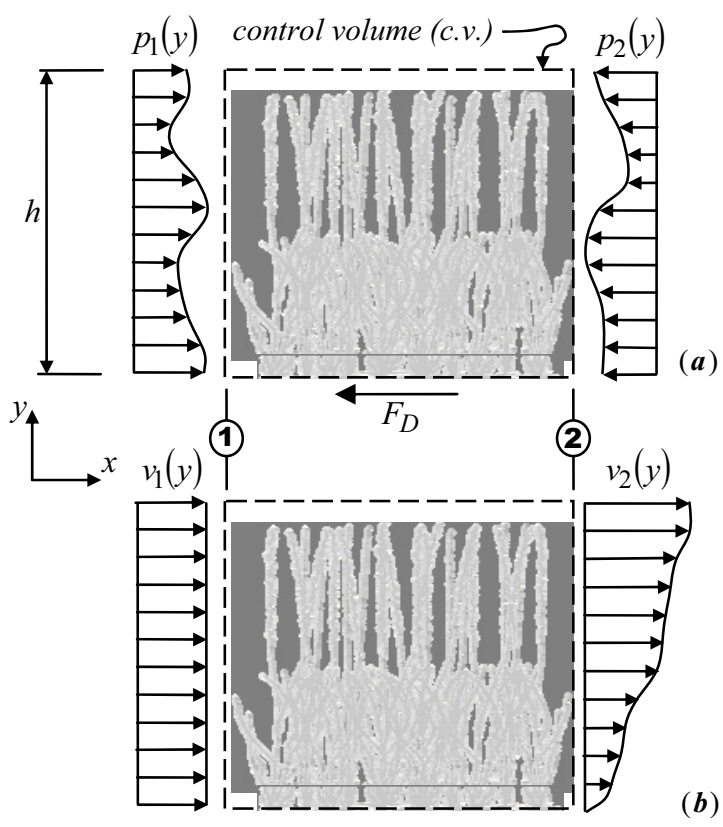

Figure 1: $\quad$ Pressure and velocity diagrams for flow through vegetation. 
For the control volume (c.v.) of Figure 1 enclosing both a stand of vegetation subjected to flow and the wind tunnel walls surrounding the vegetation, Newton's second law may be applied to the flow between Stations 1 and 2.

For a nonuniform horizontal flow from the left, the external forces are composed of the static pressure forces on the right- and left-hand boundaries of the control volume and a collective term denoted by $F_{D}$ which includes the total drag force on the vegetation (friction and pressure drags) and frictional drag on the wind tunnel walls. For momentum calculation, use the sign convention that outward flow from the control volume has positive momentum. Equating the sum of the forces to the change in momentum yields

$$
\frac{F_{D}}{w}=\int_{y=0}^{h}\left(p_{1}+\rho v_{1}^{2}\right) d y-\int_{y=0}^{h}\left(p_{2}+\rho v_{2}^{2}\right) d y=\int_{y=0}^{h}\left(2\left(p_{o}\right)_{1}-p_{1}\right) d y-\int_{y=0}^{h}\left(2\left(p_{o}\right)_{2}-p_{2}\right) d y
$$

where, $p_{1} \quad-\quad$ pressure distribution on left-hand side of c.v.,

$p_{2}$ - pressure distribution on right-hand side of c.v.,

$\left(p_{o}\right)_{1}$ - total pressure distribution on left-hand side of $c . v$.,

$\left(p_{o}\right)_{2}$ - total pressure distribution on right-hand side of c.v.,

$F_{D}$ - drag force on vegetation and wind tunnel walls,

$w$ - width of wind tunnel,

$h$ - height of vegetation and/or wind tunnel,

$\rho$ - fluid density,

$v_{1}$ - velocity distribution on left-hand side of c.v.,

$v_{2}-$ velocity distribution on right-hand side of c.v. .

\section{Vegetation density and aggregation variables considered}

Of higher priority than verifying that a total pressure difference can be used to determine drag is to ascertain what plant variables influence the actual drag and to develop a drag model for ground vegetation in terms of these variables. Using artificial plants backlighted from underneath, images such as shown in Figure 2

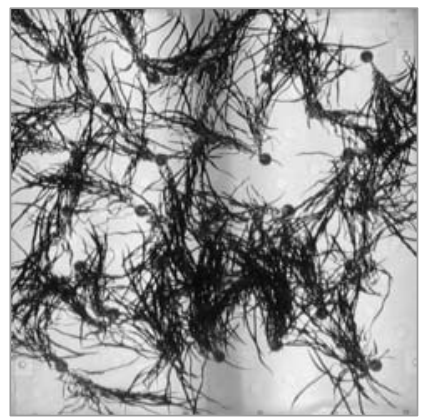

(a)

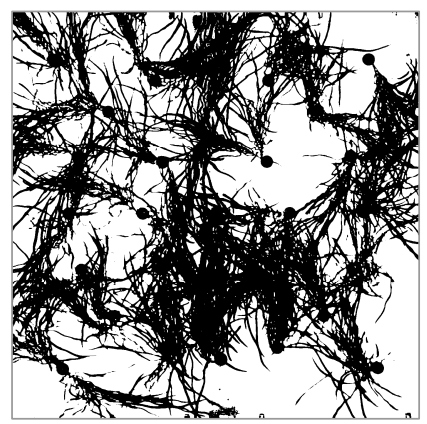

(b)

Figure 2: (a) Gray-scale, plan-view silhouette of vegetation; (b) Same photograph rendered into a black-and-white image. 
are generated. These, in turn, are read by a computer program to determine fractal dimension and lacunarity. For those unfamiliar with variables, fractal dimension is determined using the box-counting algorithm [6] and is a measure of the roughness observed in the silhouette. The lacunarity statistic is determined using the gliding-box algorithm [7] and a can be considered as the variance of the gap sizes observed in the photograph. The determined value of lacunarity varies with the size of gliding-box used; thus, some type of normalized lacunarity [8] will be reported.

From these variables and measurements of the flow rate, drag forces measured with load cells, and the geometry of the apparatus; a drag coefficient can be determined as a function of Reynolds number. Various densities, arrangements, and types of artificial plants will be used.

\section{Experimental apparatus}

Currently, testing is being carried out using the insert wind tunnel shown in Figure $3 a$. This is then inserted into the test section of the University of Toledo's low-speed wind tunnel (Figures $3 b$ and $3 c$ ). This existing wind tunnel has a $3 f t \times$ $3 f t$ test section and is utilized for its fan, which can produce velocities in excess of $150 \mathrm{mph}$. This study is only interested in velocities up to about $20 \mathrm{mph}$.

The components of the insert wind tunnel shown in Figure $3 a$ are:

(I) A Plexiglas frame to support artificial plants. The frame is mounted on load cells to allow drag measurement.

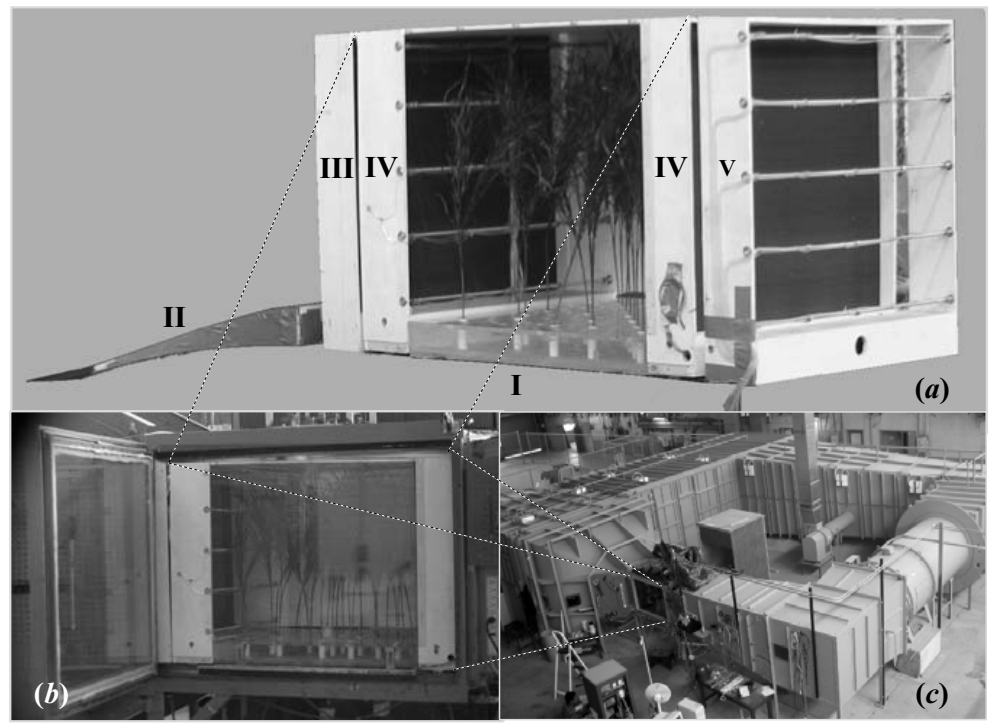

Figure 3: Current test apparatus. (a) An insert wind tunnel to be placed in ... (b) the test section of ... (c) a larger wind tunnel utilized for its fan. 
(II) A tapered section to reshape the nozzle of the larger wind tunnel as this apparatus otherwise introduces a 4-inch step in the flow.

(III) A frame holding 1/4-inch honeycombing which ensures straight flow to the Pitot tubes of Component IV.

(IV)A larger frame that spans the Plexiglas plant support. Upstream, this frame supports a static pressure probe and a grid of twenty-five Pitot tubes mounted on threaded rod. Downstream, the frame supports another honeycombing which straightens the flow before it enters the Pitot tubes of Frame V. Frame IV is mounted on load cells to determine how much of the total pressure loss (drag) is from the walls, Pitot tube grid, and honeycombing.

(V) A frame containing a Pitot tube grid and a static pressure probe.

To verify that a difference in total pressure equates to the overall drag between grids of Pitot tubes, the drag so determined should equate to the sum of the drags measured by the load cells attached to Items I and IV.

\section{Future in-situ experimental apparatus}

A portable wind tunnel along the lines of that shown in Figure 4 is ultimately envisioned. Such would probably be hoisted from a flat-bed semi trailer with the fan remaining on the trailer and a flexible duct delivering the flow. The various components of the apparatus are explained in the figure. The honeycombings are used to straighten the flow so that it impinges straight onto the Pitot tubes. The louvers and vestibule vegetation are probably not needed as the honeycombing will reshape any induced velocity profiles. Foregoing the vestibule vegetation would allow a longer test section. Alternately, honeycombing might be eliminated if Kiel-type Pitot tubes were used. A Kiel tube allows the flow to approach it from angles up to around $35^{\circ}$. The inner top over the test section might also be some type of scanner to form images such as shown in Figure 2.

If we can verify that a total pressure change can be equated to drag through ground vegetation, then the overall plant-drag database should grow rapidly and relatively inexpensively. In contrast, the U.S. Army Engineers contracts the Utah State University to use its $510 \mathrm{ft}$ long flume with potted plants mounted on load cells over a $75 f t$ test section to determine plant drag [10]. The flume is $8 f t$ wide and $6 f t$ deep. Such data collection is time, labor, and equipment intensive.

\section{Final remarks}

This work is at the point where meaningful data is being taken and rendered down to uncover what nature has hidden in terms of defining drag using fractal dimension and lacunarity. The results of this research will be reported in the near future. 


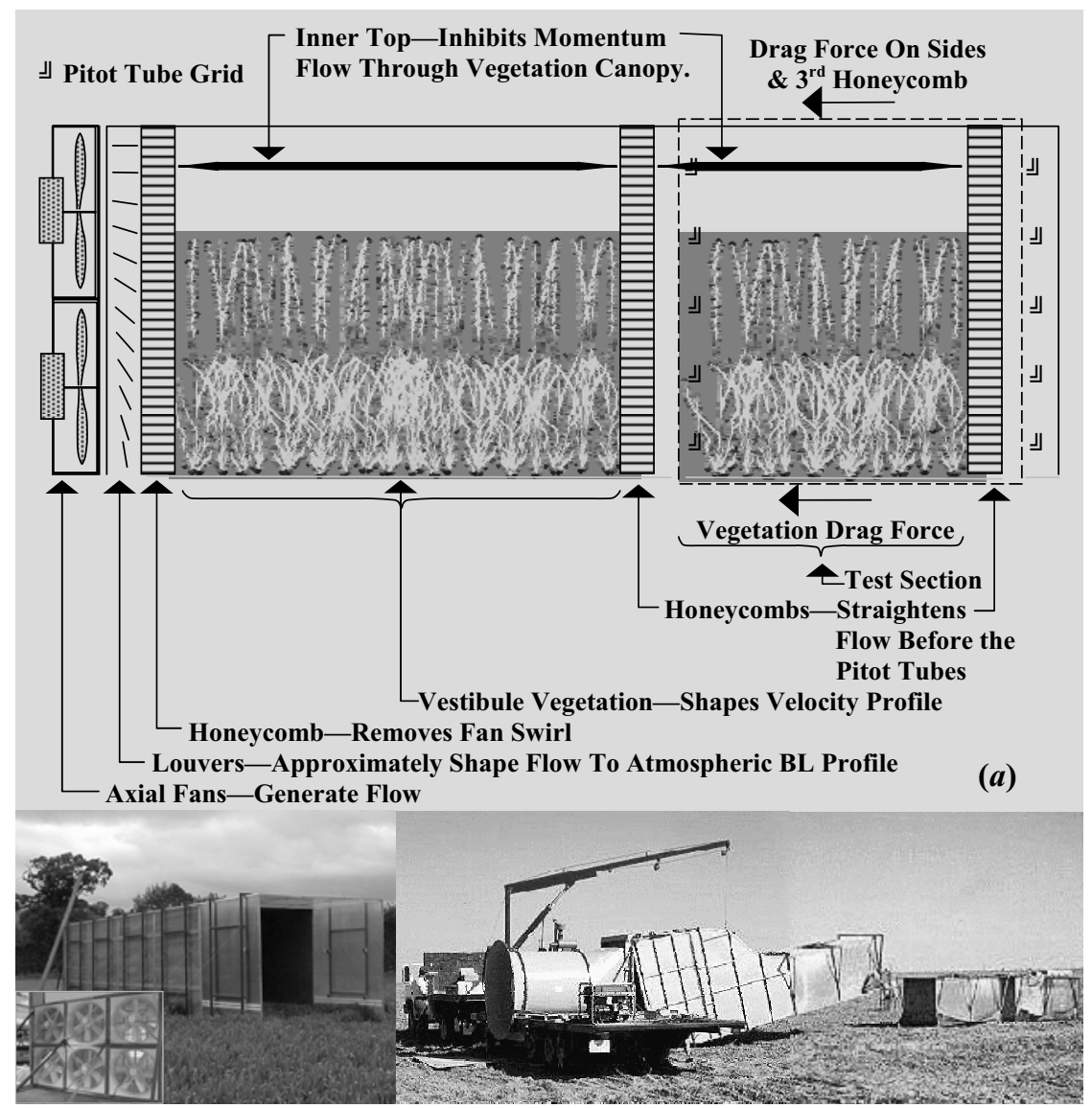

Figure 4: $\quad$ In-field wind tunnels. (a) Possible portable wind tunnel. (b) Its size would be something fitting on a semi trailer and might look like this one build by Sterling and Baker [3]. (c) The tunnel would be hoisted from the trailer. The fan might remain on the trailer as is shown in this photograph of the USDA Agricultural Research Service's wind-erosion tunnel [9].

\section{References}

[1] Fischenich, J.C., \& Dudley, S., Determining drag coefficients and areas for vegetation, EMRRP Technical Notes Collection (ERDC TN-EMRRP-SR08), US Army Engineer Research and Development Center, Vicksburg, MS, 2000. el.erdc.usace.army.mil/elpubs/pdf/sr08.pdf

[2] Sterling, M., Baker, C.J., Berry, P.M., and Wade, A., An experimental investigation of the lodging of wheat, Agricultural and Forest Meteorology, 119, 149-165, 2003. 
[3] Sterling, M., \& Baker, C., Lodging: The effect of wind induced forces on cereal crops, Infrastructure Engineering \& Management Research Centre, University of Birmingham. www.iem.bham.ac.uk/environmental/wind/sterling.htm

[4] Linn, R., Reisner, J., Colman, J., \& Winterkamp, J., Studying wildfire behavior using FIRETEC, International Journal of Wildland Fire, 11, pp. 233-246, 2002.

[5] Rae, W.H., Jr., \& Pope, A., Low-Speed Wind Tunnel Testing, $2^{\text {nd }}$ ed., John Wiley \& Sons, Inc., New York, pp. 213-214, 1984.

[6] Frame, M., \& Mandelbrot, B.B., Neger, N., Fractal Geometry, Math 190 On-Line Notes, Yale University, 2006. classes.yale.edu/Fractals/

[7] Plotnick, R.E., Gardner, R.H., \& O’Neill, R.V., Lacunarity Indices as Measures of Landscape Texture, Landscape Ecology, Vol 8, № 3, pp. 201-211, 1993.

[8] Frazer, G.W., Wulder, M.A., Niemann, K.O., Simulation and quantification of the fine-scale spatial pattern heterogeneity of forest canopy structure: A lacunarity-based method designed for analysis of continuous canopy heights, Forest Ecology and Management, Volume 214, pp. 65-90, August 2005.

[9] USDA/Agricultural Research Service Wind Tunnel. www.pnwwinderosion.wsu.edu/Windtunnel.htm

[10] Rahmeyer, W., \& Werth, D., The Study of the Resistance and Stability of Vegetation Ecosystem Plant Groupings in Flood Control Channels: Vol. 1, Utah Water Research Laboratory, Utah State University. 